\title{
Curriculum renewal at the University of lowa Carver College of Medicine
}

\author{
Marygrace Elson, MD, MME ${ }^{1}$
}

It has been more than fifteen years since the last curriculum renewal occurred. During the review for the most recent LCME review of the College, opportunities were identified to better prepare today's medical students to prepare for the future practice of medicine. These include the need for greater integration between courses and clerkships, and between material presented in the basic sciences and the clinical disciplines. As medical knowledge increases exponentially, the provider of the future will need to be well-versed in electronic information retrieval and evidence-based practice principles including biostatistics and epidemiology.

${ }^{1}$ The Department of Obstetrics and Gynecology, Roy J. and Lucille A. Carver College of Medicine, The University of lowa, lowa City, Iowa, USA

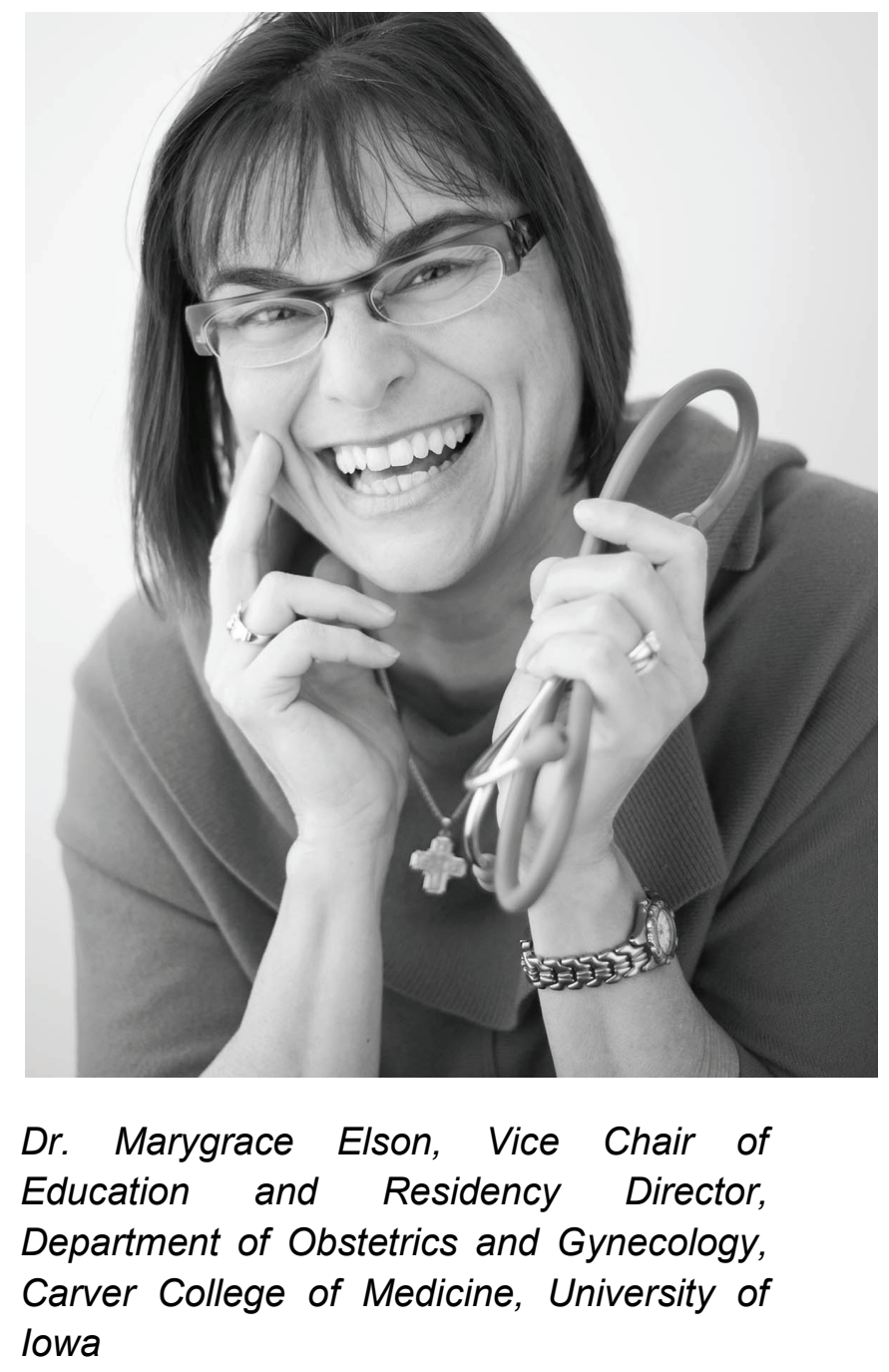

Please cite this paper as: Elson M, Curriculum renewal at the University of lowa Carver College of Medicine. Proc Obstet Gynecol. 2012 May 2(3):Article 8 [ 2 p.]. Available from: http://ir.uiowa.edu/pog/. Free full text article.

Corresponding author: Marygrace Elson, MD, MME, Department of Obstetrics and Gynecology, University of lowa, 51230 PFP, 200 Hawkins Drive, lowa City, IA 52242. Telephone (319)356-3053. marygrace-elson@uiowa.edu.

This is an Open Access article distributed under the terms of the Creative Commons Attribution 3.0 Unported License (http://creativecommons.org/licenses/by/3.0), which permits unrestricted use, distribution, and reproduction in any medium, provided the original work is properly cited. 
With this in mind a curriculum review and modeling process began in the summer of 2010. Dr. Elson participated in one of the first modeling committees and Dr. Elson and Stockdale continue to be involved on an ad hoc basis as planning goes forward.
Here is a diagrammatic of the new curriculum as envisioned. In the new curriculum it is likely that clinical clerkship experiences will begin earlier. Another feature of the new curriculum is increased elective or selective for the students. For more details and current status of the project, please follow this link: http://www.healthcare.uiowa.edu/2020/index.html

\section{Undergraduate Medical Education}

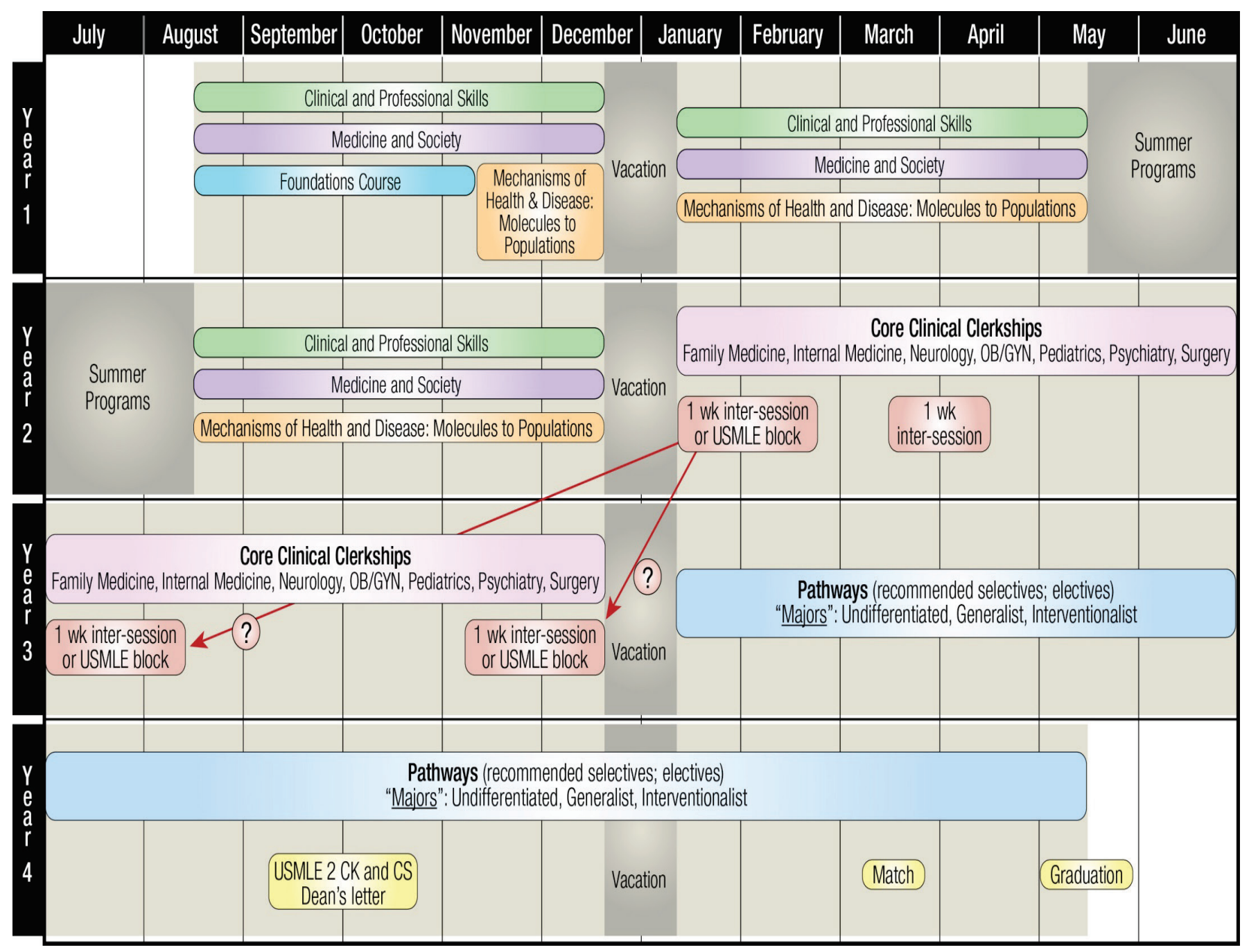

